\title{
Effects of a new arbuscular mycorrhizal fungus (Glomus iranicum) on grapevine development
}

\author{
Elisa Luciani ${ }^{1}$, Tommaso Frioni ${ }^{2}$, Sergio Tombesi ${ }^{2}$, Daniela Farinelli ${ }^{1}$, Tiziano Gardi $^{1}$, Anna Ricci $^{3}$, Paolo \\ Sabbatini ${ }^{4}$ and Alberto Palliotti ${ }^{1}$ \\ ${ }^{1}$ Dipartimento di ScienzeAgrarie, Alimentari e Ambientali, Università di Perugia, Borgo XX Giugno 74, 06121 Perugia, Italy. \\ ${ }^{2}$ Dipartimento di ProduzioniVegetaliSostenibili, Università Cattolica del Sacro Cuore, Via E.Parmense 84, 29121 Piacenza, \\ Italy. \\ ${ }^{3}$ Dipartimnto di Ingegneria Civile e Ambientale, Via G. Durante, 9306128 Perugia, Italy \\ ${ }^{4}$ Department of Horticulture, 1066 Bogue Street, East Lansing, Michigan State University, USA
}

\begin{abstract}
During the spring of 2016, one-year-old own-rooted and 3-year-old grafted vines of cv. Sangiovese were treated with MycoUp, a formulation based on a recently identified mycorrhizal fungus, Glomus iranicum var. tenuihypharum sp. nova. The results are showing an impact on the development of the root system of the two different vine groups. The treated root systems were more expanded and able to explore a higher volume of soil. We observed a significant increase in total root volume and the volume of the soil explored by the entire root system, suggesting a more efficient use of water and nutrients, phosphorus in particular, with the potential of better overcoming periods of water stress.
\end{abstract}

\section{Introduction}

In viticulture, decreases in sustainability and efficiency of perfomance in entire vineyards or specific areas are often attributable to problems related to the interaction between roots and the chemical and physical properties of the soil, often exacerbated by lack of water due to the effects of climate change. The high heterogeneity of the soils involved in grapevine culture, the orographic complexity that characterizes many grape growing areas, and the soil erosion problem that has occurred in recent decades in several viticultural areas, have accentuated and/or created a significant challenges for grape growers. It is well known that in the "soil/plant sphere" there are several factors which can easily become limiting for good vine performance, some of which include: 1) pollutants, 2) nematodes, 3) excessive compaction and anoxia, 4) reduced foodweb, etc. These critical issues require adequate cultural practices, better if preventive in nature. There is particular interest in the bio-stimulants of natural origin for optimizing vineyard management and for mitigating the negative effects induced by biotic and abiotic stresses [1]. Arbuscular mycorrhizal fungi (AMF) is one of the viable biological approaches growers can apply to soils for the mediation of specific critical situations. Between the host plant and AMF, a symbiotic relationship is established, from which both partners benefit in terms of adaptation to environmental cues, development and productivity $[2,3$, $4,5]$. In general, AMF supplies the roots with nutrients, especially phosphates, thanks to an extended extraradical mycelia network, and increases resistance to abiotic (e.g. drought, salinity and heavy metals) and biotic stresses (pathogens). In return, the host plant gives AMF part of the photosynthates (mainly sugar) [3].

In relation to the absorption of nutrients, phosphorus availability is normally reduced in soils with acid and alkaline $\mathrm{pH}$, due to the phenomenon of immobilization. The production of endo-michorrizal plants was tested invitro and in-field conditions and today it is available as a new technology for growers and nurseries [6, 7] Mycorrhized plants absorb phosphorus in two ways: 1) root hairs; 2) AMF Absorption through the radical hairs is often limited by the lack of mobility of the phosphorus in the soil. Poor mobility immediately leads to a zone of strong deficiency in the immediate vicinity of the radical epidermis. The hyphae of the AMF greatly increase the volume of soil explored by the roots, allowing the absorption of phosphorus ions from areas in which the root hairs would not otherwise have the possibility to reach. The present work reports the results obtained on young grapevines of a new formulation, named MycoUp $^{B}$ (Symborg - Biogard), based on a recently identified mycorrhizal fungus, that is Glomus iranicum var. tenuihypharum sp. nova, isolated in Spain in a clay soil, with strong water retention in high salinity and alkaline $\mathrm{pH}$. Moreover, this species is very tolerant to high concentrations of fertilizers, allowing its use even in combination with drip irrigation systems [8].

\section{Materials and Methods}

*Corresponding author: alberto.palliotti@unipg.it 
Table 1. Canopy and root development in 1-year-old self-rooted cuttings and 3-year-old vines of Sangiovese grafted on 420A rootstock treated with MycoUp and untreated at the end of 2016 growing season. Different letters indicate statistically significant differences between treatments $(\mathrm{P}<0.05)$.

\begin{tabular}{|c|c|c|c|c|c|c|c|c|}
\hline $\begin{array}{l}\text { 1-year-old self- } \\
\text { rooted cuttings }\end{array}$ & $\begin{array}{l}\text { Cane/ } \\
\text { vine } \\
\left(\mathrm{n}^{\circ}\right) \\
\end{array}$ & $\begin{array}{l}\text { Cane } \\
\text { length } \\
(\mathrm{cm}) \\
\end{array}$ & $\begin{array}{c}\text { Cane } \\
\text { diameter } \\
(\mathrm{cm})\end{array}$ & $\begin{array}{c}\text { Cane dry } \\
\text { weight } \\
\text { (g/vine) }\end{array}$ & $\begin{array}{l}\text { Leaf area } \\
\left(\mathrm{m}^{2} / \text { vine }\right)\end{array}$ & $\begin{array}{l}\text { Total length } \\
\text { of } 1^{\text {st }} \text { roots } \\
(\mathrm{cm} / \text { vine })\end{array}$ & $\begin{array}{l}\text { Average root } \\
\text { length } \\
(\mathrm{cm})\end{array}$ & $\begin{array}{l}\text { Volume of soil } \\
\text { explored by all } \\
\text { roots }\left(\mathrm{cm}^{3}\right)\end{array}$ \\
\hline Untreated & 3.0 & 18.4 & 0.90 & 2.7 & 1950 & 815 & 23.2 & 2545 \\
\hline MycoUp & 3.3 & 19.7 & 1.00 & 2.9 & 1965 & 827 & 28.5 & 4691 \\
\hline$t^{I}$ & ns & ns & ns & $\mathrm{ns}$ & ns & ns & $*$ & $*$ \\
\hline \multicolumn{9}{|l|}{ 3-year-old vines } \\
\hline Untreated & 5.0 & 24.0 & 2.25 & 8.9 & 4315 & 1870 & 18.2 & 6586 \\
\hline MycoUp & 5.0 & 27.4 & 2.14 & 10.4 & 4420 & 1980 & 23.4 & 11312 \\
\hline$t^{I}$ & $\mathrm{~ns}$ & ns & $\mathrm{ns}$ & ns & ns & $\mathrm{ns}$ & $*$ & $*$ \\
\hline
\end{tabular}

${ }^{1} *$ and $n s$ indicate significant differences at $\mathrm{P} \leq 0.05$ or not significant, respectively (Student $t$ test).

\subsection{Plant materials and experimental conditions}

During 2016, the effects of MycoUp on canopy and roots deveopment on 1- and 3-year-old grapevines were evaluated. In particular, twenty self-rooted cuttings of cv. Sangiovese grown in greenhouse and twenty 3-yearold vines of cv. Sangiovese grafted on 420A rootstock and grown in an outdoor area of the college of Agriculture of the University of Perugia (Umbria Region, Central Italy) were used. In both cases, the vines were grown in 16-liter pots with a substrate consisting of sand $(50 \%)$ and pozzolan $(50 \%)$. The composition of the substrate was chosen with the intent to enforce the effects of MycoUp, since the available literature supports the view that AMF can be more effective when nutrient poor soils [8]. Vines were subjected to a treatment with MycoUp at the beginning of May, with all vines in full vegetative activity. For each typology of vines, ten pots were inoculated with MycoUp (0,3 g/L) and the other ten pots were treated with only water (untreated). In mid April, the number of shoots per vine were adjusted by shoot thinning to 3 shoots/vine for the 1-year-old selfrooted cuttings and to 5 shoots/vine for the 3 -year-old grapevines.

\subsection{Plant growth and root morphology}

At the end of growing season, for each typology of grapevine analyzed, half of the experimental vines were destroyed and the average shoots length and diameter (at the third internode level) was measured as well as the the canes dry weight (in oven at $70{ }^{\circ} \mathrm{C}$ up to constant weight) and total leaf area per vine, by measuring all leaves just before vine destruction by an AAM-7 leaf area meter (Hayashi-Denco). To assess the effect of AMF on root morphology, the number and length of all roots with a diameter higher than $1 \mathrm{~mm}$ were measured (which represent the complex of $1^{\text {st }}$ root order). Total root volume was also determined by immersion of the entire, washed root system in a graduated cylinder filled with water and measuring the increase of volume after the immersion. Furthermore, the volume of soil explored by the roots was estimated by assimilating the root system shape to a cylinder, whose maximum height and diameter were taken with a ruler. For each vine, all roots were dried at $70{ }^{\circ} \mathrm{C}$ up to constant weight to determine the total dry weight. In 1-year-old self-rooted cuttings, the content in alcohol-soluble sugars and starch in roots (fine brown, $1.5 \pm 0.2 \mathrm{~mm}$ diam, taken at the central part of root system) and canes (at third internode level) were determined using anthrone reagent as decribed by [9]; absorbance was read at $620 \mathrm{~nm}$ with a jasco V-630 spectrophotometer.

\subsection{Visual symbiotic development and assimilable phosphorus uptake}

To evaluate the presence of AMF structures, ten young root samples per treatment ( 1 per each potted vine) were collected just before veraison (end of July) and gently washed with water, cut into $1 \mathrm{~cm}$ pieces, cleared in $10 \%$ $\mathrm{KOH}$ for $20 \mathrm{~min}$ at $80{ }^{\circ} \mathrm{C}$ and stained in $0.05 \%$ trypan blue dissolved in lacto-glycerol for $20 \mathrm{~min}$ at $80{ }^{\circ} \mathrm{C}$ following the modified method of Phillips and Hayman [10] before observation under a microscope $(60 \times$ magnification). The amount of assimilable phosphorus and the $\mathrm{pH}$ of the substrate of the pots were determined in both rhizosphere and bulk soil. The rhizosphere was isolated by picking up the roots together with the adhering soil [11]. The roots with a diameter larger than $2 \mathrm{~mm}$ were discarded. After a light shaking to detach the weakly adhering soil particles, which were then added to the bulk soil, the remaining soil material firmly adhering to the fine roots was considered as rhizosphere and was recovered by further shaking and gentle brushing. The rhizosphere and the bulk soil of each sample were allowed to air dry for the determination of the assimilable phosphorus and $\mathrm{pH}$. The soil $\mathrm{pH}$ was determined potentiometrically in water, whereas the assimilable phosphorus was determined with Olsen method.

\subsection{Statistical analysis}

Data were subjected to analysis of variance (ANOVA) and, for each typology of grapevine, data were compared using a Student $t$ test $(\mathrm{P}<0.05$ level $)$. 


\section{Results}

At the end of the season, the cane length and diameter and the total cane dry weight as well as the total leaf area per vine were not influenced by MycoUp treatment in both 1-year self-rooted cuttings and 3-yearsold grafted vines (Table 1).

Unlike the canes, the root system, in both types of vines analyzed, showed a definitive modified architecture. In AMF vines, a complex of $1^{\text {st }}$ order roots (or pioneer with support and transport functions) and $2^{\text {nd }}$ order (or exploration) and lateral (i.e. those that start from the support roots and assume a vertical direction with the function of connection with the absorbent capillary) roots were found more developed and extended.

The total length of $1^{\text {st }}$ order roots in both typology of AMF vines was unaffected, whereas, in comparison to untreated vines, the average length of the single $1^{\text {st }}$ order roots was greater by about $23 \%$ and $29 \%$ in 1 -yearrooted cuttings and 3-year-oldgrafted vines, respectively (Table 1). The combined effect of these two changes, in AMF vines, reduced the number of $1^{\text {st }}$ roots per vine by about $18 \%$ (35 vs 29 roots/vine in 1-year-old self-rooted cuttings) and $17 \%$ (103 vs 85 roots/vine in 3-year-old vines), respectively (Table 1 ).

This diversity of root architecture determined different root volume, which in cuttings and grafted vines was increased by about $106 \%$ and $36 \%$ respectively (Fig. 1A) as well as the root dry weight which was increased by about $45 \%$ and $30 \%$ respectively (Fig. 1B).

These modifications in the size of the root systems caused a different volume of soil to be explored, which, in both typology of vines, was much greater in the vines treated with the G. iranicum (Table 1).
At the end of 2016, on the roots of 1-year-old self-rooted cuttings treated with $G$. iranicum, a significantly higher starch content was found, with an increase of $25 \%$ compared to untreated vines (Fig. 2). In both vine organs analyzed, the soluble sugars content did not show detectable differences.

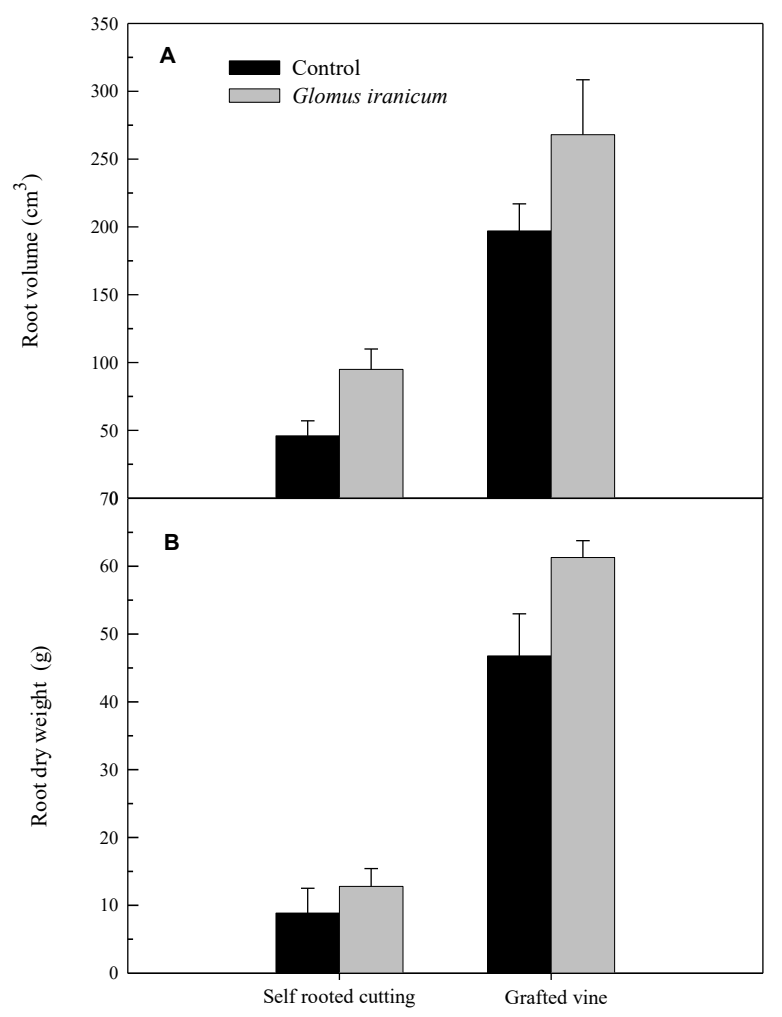

Fig. 1. Root volume (A) and total root dry weigth (B) of 1year-old self-rooted cuttings and 3-year-old grafted vines of cv. Sangiovese inoculated with G. iranicumand untreated. Data show the average value \pm S.E.

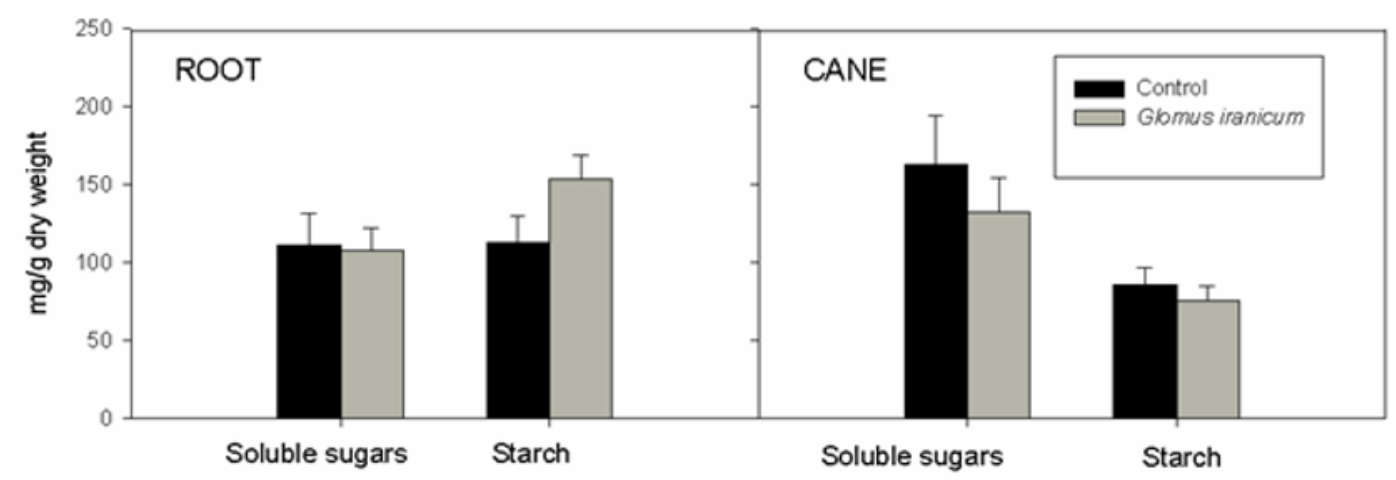

Fig. 2. Content of alchool-soluble sugars and starch in roots (diameter 0.8-1 mm) and canes (third internode level) of 1year-old self-rooted cuttings subjected to inoculation with G. iranicum and untreated vines. Data show the average value \pm S.E. 


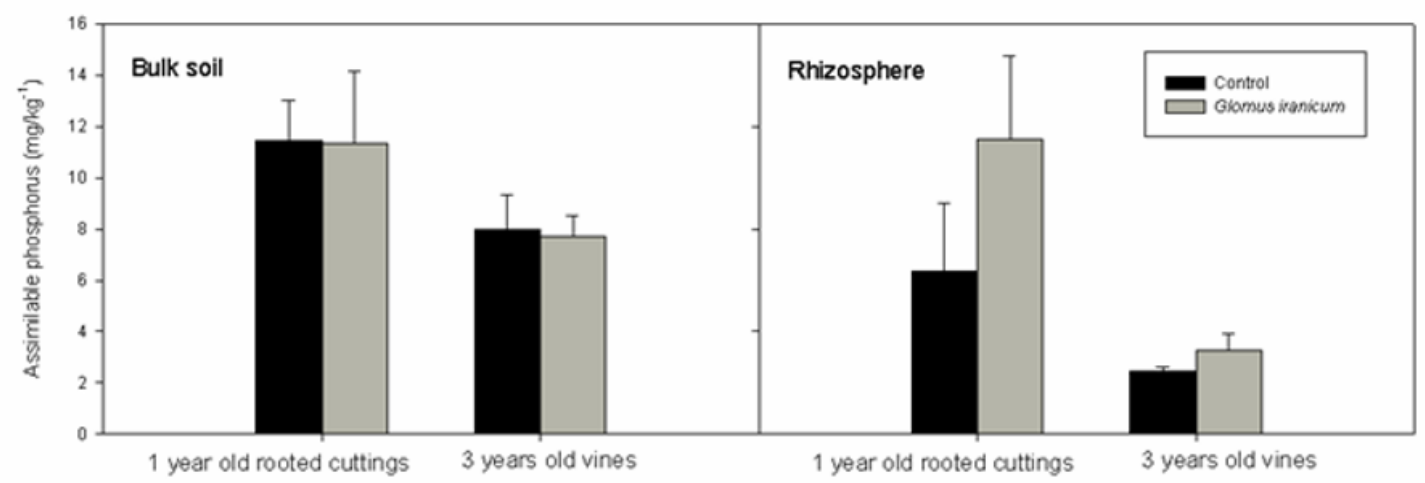

Fig. 3. Amount of assimilable phosphorus in bulk soil and rhizosphere of 1-year-old self-rooted cuttings and 3-year-old grafted Sangiovese vines inoculated with $G$. iranicum and untreated vines. Data show the average value \pm S.E.

The results of the chemical analysis of the soil around the root systems confirmed that the main benefit of the AMF symbiosis for the vines was an enhanced absorption of assimilable phosphorus, frequently a limiting factor in plant growth due to its poor solubility and mobility in the soil. In both types of vines analyzed and, opposite to the bulk soil, the content of assimilable phosphorus found in the rhizosphere of AMF vines was higher $(+80 \%$ in 1-year-old self-rooted cuttings and $+31 \%$ in 3 -year-old grafted vines) (Fig. 3).

Regardless of both the type of vine analyzed and its treatment, $\mathrm{pH}$ value of the rhizosphere was $\sim 7.0$, which represents an optimal value for the solubilization of inorganic phosphorus, whereas the $\mathrm{pH}$ of respective bulk soil was $\sim 8.1$.

Microscopic observations of mychorrized roots, made at the end of July, showed clear arbuscular structures from $G$. iranicum var. tenuihypharum sp. nova inside the roots' sub-epidermal cells of all the 10 treated vines (Fig. 4 left), whereas at the root surfaces an evident and developed hyphen were detected (Fig. 4 right).
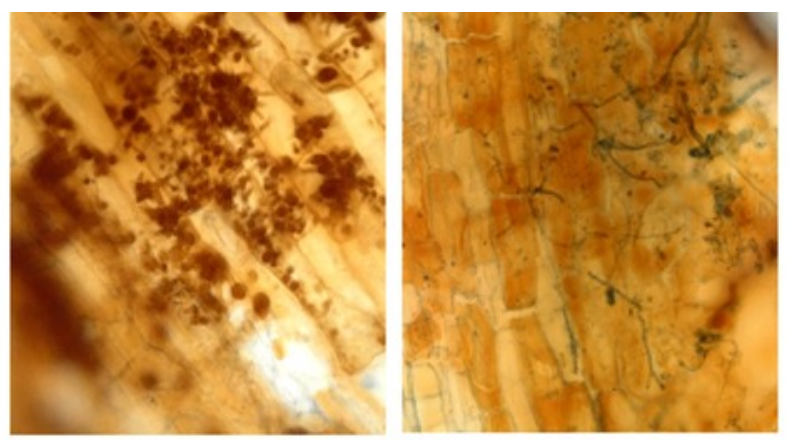

Fig. 4. Mycorrhizal arbusculars in root cells of 1-year-old selfrooted cuttings of Sangiovese (left), external hyphae in a mycorrhized root (right).

\section{Discussion}

During the first year of application, contrary to canopy development, treatment with a new formulation based on a recently identified mycorrhizal fungus, called
MycoUp (Symborg - Biogard) of Glomus iranicum var. tenuihypharum sp. Nova, was able to modify the root architecture in both types of grapevines used in this experiment. In fact, compared to untreated vines, the number of roots of $1^{\text {st }}$ order was reduced in favor of a greater relative length, whereas the $2^{\text {st }}$ order roots were more widely spaced. These changes increase the total root length, total root volume and root dry weight, and the volume of the soil explored by the root system. A common effect of mycorrhization is an increase in lateral root development, perhaps in order to increase the number of suitable soil niches for root exploitation [12] and similar results were previously reported by other authors $[13,14,15]$.

The possible causes of improving root system architecture may be direct as well as indirect; the first include the production and action of AMF fungal exudates, while the second are mainly related to increased nutrient uptake, particulary phosphorus, and modulation of hormone balance [16].

In the AMF self-rooted vines, the quantity of dry matter produced during the growing season and invested in the roots was $75 \%$ against $66 \%$ in untreated vines, whereas in 3-year-old mycorrhized vines, these percentages rise at $91 \%$ and $87 \%$, respectively. Contrary to our outdoor area experiment, where the AMF vines had lower root:shoot ratio [17], we found an increase in this parameter, probably because the growth of the canes was unaffected by this AMF. In particular, in 1-year-old self-rooted vines the root:shoot ratio increased from 1.96 in untreated vines to 2.95 in AMF ones, whereas in 3year-old vines these values changed from 6.76 in untreated vines to 9.75 in AMF vines.

According to results reported by Nicolàs et al. [8] in Crimson grapevines inoculated with Glomus iranicum var. tenuihypharum sp. nova, a greater efficiency in absorbing phosphorous was found also in cv. Sangiovese as well as accumulation of starch in the roots, which contributes to the development of a larger root system and this could favour a faster vegetative growth in the following spring. 


\section{Conclusions}

The results confirm the potential viticultural applicability of this new formulation (MycoUp $\left.{ }^{\circledR}\right)$ based on a recently identified mycorrhizal fungus Glomus iranicum var. tenuihypharum sp. Nova. The formulation, when applied on two different types of vines, was able to improve the development of the root system in young grapevines, which in turn became more expanded, with an increased ability to explore a higher volume of soil. Consequntly, this allows a more efficient use of nutrients and water and the ability to better overcome periods of water stress.

The adoption of AMF seems to be a promising tool, especially in relation to nursery production and to the enhancement of vine estabilishment and development after planting.

This research was funded by BIOGARD (Division of CBC, Europe). The authors are grateful to Dr. Massimo Benuzzi and Dr. Mauro Piergiacomi for critical suggestions during our research and helpful discussions

\section{References}

1. T. Frioni, P. Sabbatini, S. Tombesi, J. Norrie, S. Poni. M. Gatti, A. Palliotti. Sci. Hort. 232, 97-106 (2018)

2. E. George, V. Römheld, H. Marschner. In: Manthey J.A., Crowley D.E., Luster D.G. (Eds.), Biochemistry of metal micronutrient in the rhizosphere. CRC, Boca Raton, Florida, pp. 93-109. (1994)

3. D.P. Wright, D.J. Read, J.D. Scholes. Plant, Cell Environ. 21, 881-91 (1998)

4. J.M. Ruiz-Lozano. Mycorrhiza. 13, 309-317 (2003)

5. S. Trouvelot, L. Bonneau, D. Redecker, D. Van Tuinen, M. Adrian, D. Wipf, . Agron. Sustain. Dev. 35, 1449-1467. (2015)

6. M. Giovannetti, A. Schubert, M.C. Cravero, L. Salutini. Biol. Fertil. Soils 6, 120-124. (1988)

7. F. Ravolanirina, S. Gianinazzi, A. Trouvelot, M. Carre. Agric. Ecosyst. Envir. 29, 323-327. (1990).

8. E. Nicolás, J. F. Maestre-Valero, J. J. Alarcón, F. Pedrero, J. Vicente-Sánchez, A. Bernabé, J. GómezMontiel, J. A. Hernández, F. Fernández. J. Agric. Sci. 3, 1-13 (2014)

9. F.A. Loewus. Anal. Chem. 24, 219 (1952)

8. J.M. Phillips, D.S. Hayman. Trans. Brit. Mycol. Soc. 55, 158-161 (1970).

10. M. De Feudis,V.Cardelli, L. Massaccesi, R. Bol, S. Willbold, S. Cocco, G. Corti, A. Agnelli. Geoderma 276, 53-63 (2016)

11. M.J. Harrison. Ann. Rev. Microb. 59, 19-42 (2005)

12. L. Schellenbaum, G. Berta, F. Ravolanirina, B. Tisserant, S. Gianinazzi, A.H. Fitter. Ann. Bot. 68, 135-141 (1991)

13. S. Scannerini, A. Fusconi, M. Mucciarelli. Seckback J., Ed. Dordrecht: Kluwer, 427-447 (2001)
14. A. Hodge, G. Berta, C. Doussan, F. Merchan, M. Crespi. Plant and Soil 321, 153-187 (2009)

15. A. Fusconi. Ann. Bot.113, 19-33 (2014)

16. N. Feddermann, R. Finlay, T. Boller, M. Elfstrand. Fung. Ecol.3, 1-8 (2010) 